\title{
Praktikalitas dan Efektivitas Modul Logika Matematika Berbasis Problem Based Learning (PBL)
}

\author{
Riska Novia Sari ${ }^{1}$, Yessy Yusnita ${ }^{2}$ \\ ${ }^{1,2}$ Program Studi Pendidikan Matematika, Universitas Riau Kepulauan. \\ E-mail: ${ }^{1}$ riskanovia30@gmail.com
}

\begin{abstract}
Abstrak
Tujuan penelitian ini adalah untuk mengembangkan modul logika matematika berbasis problem based learning yang praktis dan efektif. Metode penelitian yang digunakan yaitu metode pengembangan (R\&D).model pengembangan yang digunakan adalah model 4-D yang terdiri dari 4 tahap, yaitu tahap pendefinisian (define), tahap perancangan (design), tahap pengembangan (develop), dan tahap pendiseminasian (disseminate). Pada penelitian ini hanya dilakukan 3 tahap, yaitu tahap pendefinisian, tahap perancangan, dan tahap pengembangan.Subjek penelitian adalah 21 orang mahasiswa Program Studi Pendidikan Matematika di Universitas Riau Kepulauan.Instrument yang digunakan yaitu berupa angket respon mahasiswa untuk memperoleh data praktikalitas modul dan tes uraian untuk memperoleh data efektivitas modul.Data hasil angket dihitung rata-rata per aspek dan dihitung rata-rata skor total dan dibandingkan dengan kriteria yang telah ditetapkan.Sedangkan data hasil belajar dihitung persentase mahasiswa yang memperoleh nilai lebih dari 68 . Hasil analisis data angket respon mahasiswa diperoleh rata-rata skor total untuk semua aspek yaitu 3,40 yang termasuk kategori baik. Sedangkan analisis data tes hasil belajar diperoleh sebesar 71,42\% mahasiswa mendapatkan nilai lebih dari 68 dan rata-rata tes hasil belajar sebesar 76,9. Berdasarkan analisis dapat disimpulkan bahwa modul yang dikembangkan praktis digunakan dalam perkuliahan logika matematika dan efektif dalam menunjang kompetensi mahasiswa.
\end{abstract}

Kata Kunci: modul, logika matematika, problem based learning

\section{Practicality and Effectiveness of Mathematical Logic Module Based on Problem Based Learning (PBL)}

\begin{abstract}
The purpose of this study was to develop a mathematical logic module based on problem-based learning that is practical and effective. The research method used is the development method ( $R \& D)$. The development model used is a 4-D model consisting of 4 Stage, namely define, design, develop phase, and disseminate stage. In this study, only three phase was carried out, namely define, design and develop. Research subjects were 21 people student of Mathematics Education Study Program at the University of Riau Kepulauan. The instrument used in the form of student response questionnaires to obtain practical data modules and tests description to obtain module effectiveness data. Questionnaire result data is calculated on average per aspect and the average total score is calculated and compared to the predetermined criteria. Whereas data Learning outcomes are calculated by the percentage of students who scored more than 68. Results of data analysis student response questionnaires obtained an average total score for all aspects, namely 3.40 included the good category. While the analysis of the data on the learning outcomes test was received at $71.42 \%$ of students, get a score of more than 68 and the average learning outcome test is 76.9. Based on the analysis it was concluded that the modules were developed practically were used in mathematical logic lectures and effective in supporting student competence
\end{abstract}

Keywords: module, mathematical logic, problem based learning 


\section{PENDAHULUAN}

Penalaran merupakan aspek penting dalam pembelajaran matematika.NCTM(2000) berpendapat "mathematical reasoning and proof offer powerful ways of developing and expressing insights about a wide range of phenomena...being able to reason is essential to understanding mathematics". Pernyataan tersebut memiliki makna yaitu penalaran matematika adalah cara ampuh dalam mengembangkan wawasan tentang berbagai hal, mampu bernalar merupakan komponen penting dalam memahami matematika. Hal ini didukung oleh pernyataan (Wahyudin, 2008) bahwa kemampuan untuk menggunakan nalar sangatlah penting untuk memahami matematika. Dengan mengembangkan ide-ide, mengeksplorasi fenomena, menjustifikasi hasil-hasil, dan memanfaatkan dugaan-dugaan matematis di dalam semua area muatan dan dengan harapan bahwa matematika itu dapat dipahami.

Salah satu mata kuliah yang dapat mengasah kemampuan penalaran mahasiswa adalah mata kuliah logika matematika(Kusumah, 1986);(Sukirman, 2005). Logika merupakan ilmu dan kecakapan bernalar, serta memuat aturan-aturan untuk pemikiran yang tepat(Hidayati, 2013). Aturan tersebut dapat diterapkan dalam kehidupan sehari-hari misalnya membuktikan suatu kebenaran ataupun menganalisis suatu persoalan dan mengambil kesimpulan.Di Universitas Riau Kepulauan khususnya program studi pendidikan matematika, mata kuliah logika matematika merupakan mata kuliah wajib bagi mahasiswa semester 2 dengan beban sebanyak 3 sks.Materi-materi yang dipelajari dalam mata kuliah logika matematika termasuk dalam kurikulum matematika di tingkat SMA/MA.Sehingga lulusan prodi pendidikan matematika diharapkan menjadi guru matematika yang mempunyai bekal yang cukup untuk mengajar di SMA/MA nantinya.

Untuk mencapai tujuan tersebut haruslah didukung oleh ketersediaan buku ajar ataupun bahan ajar mata kuliah logika matematika.Namun berdasarkan pengalaman peneliti yang mengampu mata kuliah logika matematika di Program Studi Pendidikan Matematika Universitas Riau Kepulauan, ketersediaan buku ajar masih menjadi kendala.Referensi utama yang digunakan yaitu buku cetakan lama (cetakan tahun 1986) yang didalamnya terdapat simbol-simbol yang kurang lazim digunakan oleh mahasiswa. Selain itu inisiatif mahasiswa untuk mencari sumber belajar lain juga sangat kurang, mahasiswa masih mengandalkan sumber belajar yang diberikan dosen. Hal ini juga diduga menjadi penyebab rendahnya capaian prestasi belajar mahasiswa pada mata kuliah logika matematika. Berdasarkan nilai mahasiswa Program Studi Pendidikan Matematika semester 2 tahun pelajaran 2016/2017, persentase nilai tertinggi yang diperoleh mahasiswa yaitu nilai $\mathrm{C}$ sebesar $47 \%$ diikuti oleh nilai B sebesar 33\% dan A sebesar 12\%, serta D sebesar 8\%.

Berdasarkan permasalahan di atas perlu dikembangkan suatu bahan ajar yang dapat memfasilitasi mahasiswa dalam mempelajari mata kuliah logika matematika dan diharapkan dengan dikembangkan bahan ajar ini dapat meningkatkan capaian prestasi belajar mereka.Dalam hal ini bahan ajar yang dikembangkan yaitu berupa modul. Modul merupakan alat pembelajaran yang disesuaikan dengan kebutuhan belajar pada pelajaran tertentu untuk keperluan proses pembelajaran tertentu(Andriadi, Fitraiani, \& Suhandri, 2018). Sedangkan 
menurut (Tjiptiany, As'ari, \& Muksar, 2016) modul adalah bahan ajar yang disusun secara sistematis dan menarik yang mencakup isi materi, metode, dan evaluasi yang dapat digunakan secara mandiri. Agar dalam proses perkuliahan mahasiswa terlibat aktif, maka akan dikembangkan suatu modul logika matematika berbasis pendekatan Problem Based Learning (PBL).

Salah satu tujuan pemilihan PBL yaitu agar konsep-konsep logika tidak diterima secara langsung oleh mahasiswa dari dosen, namun dosen memberikan berbagai masalah menantang yang berfungsi sebagai stimulus dan pemicu mahasiswa berpikir sehingga mahasiswa terlibat aktif dalam pembelajaran serta memfasilitasi mahasiswa untuk menemukan konsep. Hal ini sejalan dengan pendapat (Ikman, Hasnawati, \& Rezky, 2016), (Mikrayanti, 2016), (Husniati, Suciati, \& Maridi, 2016) bahwa pembelajaran PBL diawali dengan menghadapkan siswa dengan masalah matematika, dengan segenap kemampuan yang telah dimilikinya, siswa dituntut untuk menyelesaikan masalah-masalah tersebut dan menemukan konsep serta prinsipprinsip dari suatu pengetahuan.

Oleh karena itu, pada penelitian terdahulu, peneliti telah mengembangkan modul logika matematika berbasis PBL yang telah diuji kevalidannya oleh 3 validator yang terdiri dari 2 orang validator ahli materi dan 1 orang validator ahli media. Hasil penilaian validator ahli materi yang meliputi aspek kelayakan isi, penyajian dan kebahasaan menunjukkan rata-rata skor 3,65 dengan kriteria sangat valid. Sedangkan total penilaian dari validator ahli media menunjukkan rata-rata skor 3,8 dengan kriteria sangat valid. Sehingga dihasilkanlah modul logika matematika yang valid dan layak untuk digunakan dalam perkuliahan logika matematika. Penelitian ini merupakan penelitian lanjutan dari penelitian terdahulu yang bertujuan untuk melihat praktikalitas penggunaan modul dan bagaimana keefektifan modul dalam menunjang kompetensi mahasiswa pada mata kuliah logika matematika.

\section{METODE}

Penelitian ini merupakan jenis penelitian pengembangan (Research and Development/R\&D). Penelitian pengembangan adalah penelitian untuk mengembangkan dan menghasilkan produk-produk pendidikan berupa materi, media, alat dan strategi pembelajaran, evaluasi, dan sebagainya untuk mengatasi masalah pendidikan, dan bukan untuk menguji teori (Ruseffendi, 2005). Modul logika matematika dikembangkan menggunakan model 4-D, yaitu tahap pendefinisian (define), tahap perancangan (design), tahap pengembangan (develop), dan tahap pendiseminasian (disseminate). tahappendefinisian, perancangan, dan pengembangan (validasi) sudah dilakukan pada penelitian terdahulu. Sehingga pada penelitian ini hanya fokus pada tahap pengembangan selanjutnya yaitu praktikalitas dan efektivitas.Adapun langkah-langkah pelaksanaan keduanya seperti berikut.

1. Praktikalitas

Praktikalitas merupakan tingkat keterpakaian modul logika matematika berbasis PBLoleh mahasiswa. Aspek praktikalitas yang diukur yaitu aspek tampilan, penyajian materi dan aspek manfaat.Modul yang telah dinyatakan valid, selanjutnya dilakukan ujicoba terhadap 21 orang mahasiswa program studi pendidikan matematika di FKIP Universitas Riau 
Kepulauan.Modul dikatakan praktis jika hasil penilaian menunjukkan kriteria baik sesuai dengan kriteria yang telah ditentukan. Jika hasil belum praktis, maka akan dilakukan perbaikan sesuai dengan saran responden.

2. Efektivitas

Tahap ini dilakukan setelah modul dinyatakan praktis. Kegiatan dipusatkan untuk mengevaluasi apakah modullogika matematika berbasis PBL dapat digunakan untuk mencapai tujuan yang efektif dalam meningkatkan kualitas dan prestasi belajar mahasiswa. Aspek efektifitas yang diamati dalam proses perkuliahan yang menggunakan modullogika matematika berbasis PBL dalam hal ini khususnya yaitu hasil belajar mahasiswa.Hasil belajar diperoleh melalui tes, kemudian modul dikatakan efektif apabila lebih dari $70 \%$ mahasiswa memperoleh nilai $\geq 68$.

Instrumen yang digunakan dalam penelitian ini yaitu berupa angket mahasiswa untuk mendapatkan data praktikalitas dan tes hasil belajar untuk mendapatkan data efektivitas.Angket terdiri dari 17 pernyataan dengan pilihan jawaban sangat setuju, setuju, kurang setuju, dan tidak setuju.Sedangkan instrument tes berbentuk tes uraian yang terdiri dari 3 soal.

Hasil skor rata-rata untuk setiap aspek penilaian dihitung menggunakan rumus:

Keterangan :

$$
\bar{x}=\frac{\sum x}{n}
$$

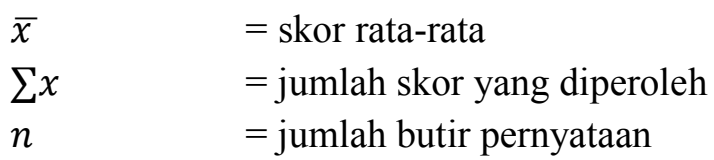

Skor rata-rata yang diperoleh kemudian dikonversikan menjadi data kualitatif skala lima seperti ditunjukkan pada tabel berikut (Widoyoko, 2017):

Tabel 1. Konversi Data Kualitatif Skala Lima dalam Penilaian Modul

\begin{tabular}{cc}
\hline Rentang Skor & Kriteria \\
\hline $\bar{x}>\mathrm{M}_{\mathrm{i}}+1,8 \mathrm{SB}_{\mathrm{i}}$ & Sangat baik \\
$\mathrm{M}_{\mathrm{i}}+0,6 \mathrm{SB}_{\mathrm{i}}<\bar{x} \leq \mathrm{M}_{\mathrm{i}}+1,8 \mathrm{SB}_{\mathrm{i}}$ & Baik \\
$\mathrm{M}_{\mathrm{i}}-0,6 \mathrm{SB}_{\mathrm{i}}<\bar{x} \leq \mathrm{M}_{\mathrm{i}}+0,6 \mathrm{SB}_{\mathrm{i}}$ & Cukup baik \\
$\mathrm{M}_{\mathrm{i}}-1,8 \mathrm{SB}_{\mathrm{i}}<\bar{x} \leq \mathrm{M}_{\mathrm{i}}-0,6 \mathrm{SB}_{\mathrm{i}}$ & Kurang baik \\
$\bar{x} \leq \mathrm{M}_{\mathrm{i}}-1,8 \mathrm{SB}_{\mathrm{i}}$ & Tidak baik \\
\hline
\end{tabular}

Keterangan :

$$
\begin{array}{ll}
\bar{x} & =\text { Skor rata-rata } \\
\mathrm{M}_{\mathrm{i}} & =\frac{1}{2}(\text { Skor maksimal ideal }+ \text { Skor minimal ideal }) \\
\mathrm{SB}_{\mathrm{i}} & =\frac{1}{6}(\text { Skor maksimal ideal }- \text { Skor minimal ideal })
\end{array}
$$

Tabel 1 dikembangkan dengan skor maksimal ideal adalah empat dan skor minimal ideal adalah satu. Tabel pengembangan ditunjukkan pada Tabel 2 berikut: 
Tabel 2. Kriteria Respon Mahasiswa terhadap Modul yang Dikembangkan

\begin{tabular}{cc}
\hline Rentang Skor & Kriteria \\
\hline $\bar{x}>3,4$ & Sangat baik \\
$2,8<\bar{x} \leq 3,4$ & Baik \\
$2,2<\bar{x} \leq 2,8$ & Cukup baik \\
$1,6<\bar{x} \leq 2,2$ & Kurang baik \\
$\bar{x} \leq 1,6$ & Tidak baik \\
\hline
\end{tabular}

Modul dikatakan praktis apabila minimal kriteria yang dicapai adalah kriteria baik.

\section{HASIL DAN PEMBAHASAN}

Hasil perancangan modul logika matematika berbasis PBL terdiri dari 3 Bab dimana setiap babnya memuat pendahuluan, kompetensi, uraian materi, contoh soal, isian titik-titik yang berfungsi untuk membantu mahasiswa dalam melakukan penyelidikan dan latihan mandiri di akhir bab. Berikut contoh komponen-komponen dalam modul logika matematika berbasis PBL:

a. Penyajian masalah/orientasi pada masalah dalam uraian materi

Sebelum uraian materi mahasiswa dihadapkan pada permasalahan yang harus mereka pecahkan secara bersama dalam kelompok, adapun contoh permasalahan logika yang diberikan sebagai berikut.

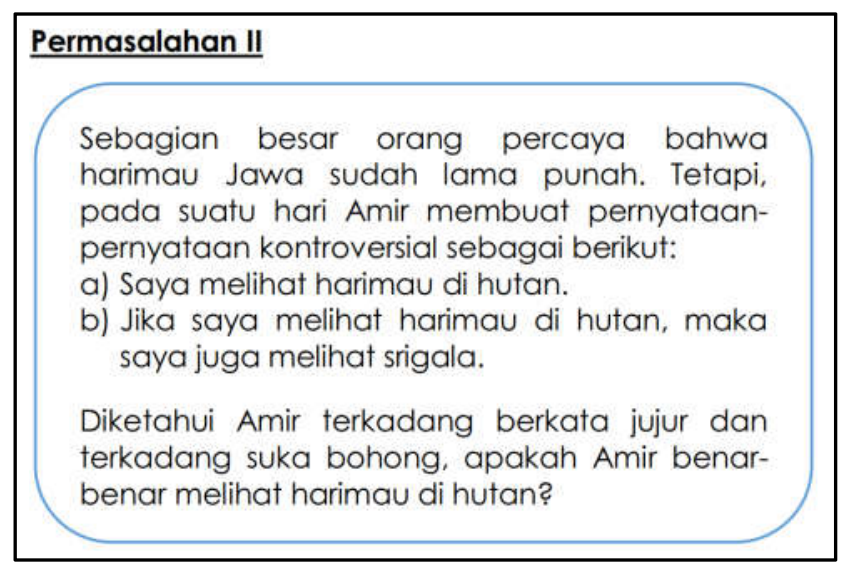

Gambar 1. Masalah pada Modul

b. Mengorganisasikan kegiatan belajar mahasiswa

Yaitu mengorganisasikan mahasiswa ke dalam kelompok-kelompok belajar untuk mendiskusikan permasalahan yang diberikan. 


\section{Petunjuk:}

a. Sebelum menyelesaikan permasalahan di atas, bentuklah kelompok kecil yang terdiri dari 3 orang.

b. Diskusikanlah permasalahan tersebut dengan anggota kelompok dan buatlah hasil diskusi pada kertas yang sudah dibagikan.

Gambar 2. Mengorganisasikan Mahasiswa

c. Membantu penyelidikan

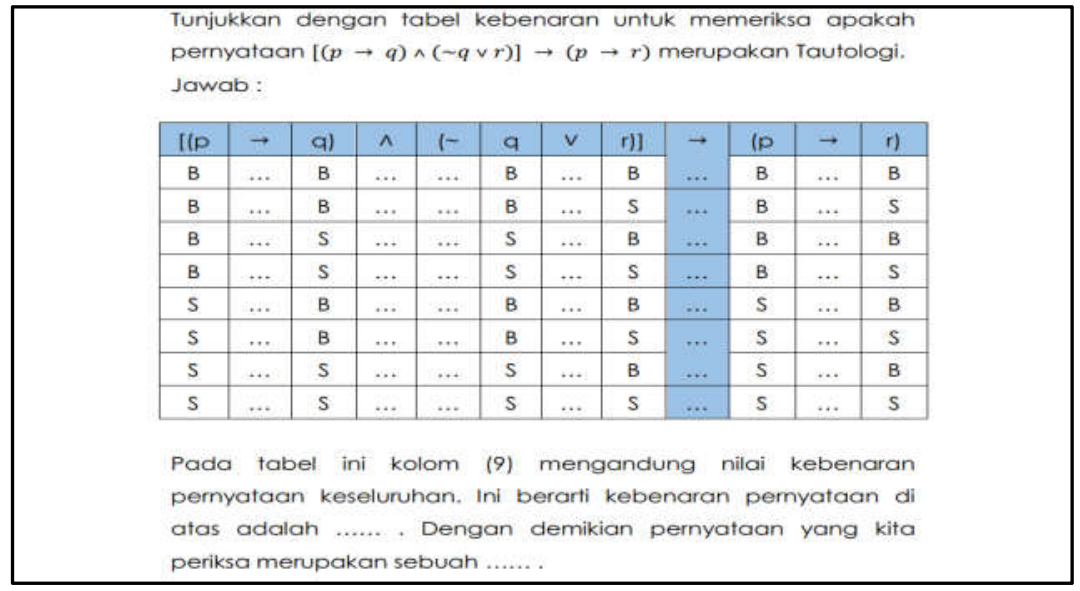

Gambar 3. Membantu Mahasiswa dalam Penyelidikan

d. Menyajikan dan mengembangkan hasil karya

Dalam hal ini masing-masing kelompok menyampaikan solusi dari permasalahan yang diberikan berdasarkan hasil diskusi kelompok.

e. Evaluasi berupa latihan mandiri

D. Sebuah pulau didiami oleh dua suku asli. Penduduk suku pertama selalu mengatakan kebenaran, sedangkan dari suku lain selalu mengatakan kebohongan. Anda datang ke pulau tersebut dan bertanya kepada seorang penduduk setempat apakah ada emas di pulau tersebut atau tidak. Ia menjawab "ada emas di pulau ini jika dan hanya jika saya selalu mengatakan kebenaran". Apakah ada emas di pulau tersebut?

E. Periksalah dengan tabel kebenaran apakah pernyataan berikut merupakan Tautologi, Kontradiksi atau Kontingen,

1. $[\{p \vee q) \rightarrow r\} \wedge(s \wedge t)] \rightarrow u$

2. $\sim(p \wedge r) \vee[\sim p \wedge \sim q) \rightarrow r]$

\section{Gambar 4.Latihan Mandiri}

Setelah modul dinyatakan valid oleh ketiga validator, selanjutnya dilakukan ujicoba modul untuk melihat praktikalitas modul yang dikembangkan.Ujicoba dilakukan pada mahasiswa Program Studi Matematika Universitas Riau Kepulauan yang mengambil mata kuliah logika matematika berjumlah 21 orang. Materi yang diujikan terdiri dari 2 bab yaitu 
pengantar logika serta pernyataan dan operasinya. Selanjutnya mahasiswa diberikan angket untuk memperoleh data praktikalitas dan tes untuk memperoleh data efektivitas.

Angket respon mahasiswa diberikan di akhir pertemuan perkuliahan.Angket respon mahasiswa ditinjau dari aspek tampilan, aspekpenyajian materi dan aspek ketertarikan.Berikut ringkasan hasil penilaian setiap aspeknya.

Tabel 3. Hasil Uji Praktikalitas Modul

\begin{tabular}{lcc}
\hline \multicolumn{1}{c}{ Aspek } & Rata-rata skor & Kriteria \\
\hline Tampilan & 3,46 & Sangat baik \\
Penyajian Materi & 3,36 & Baik \\
Ketertarikan & 3,38 & Baik \\
\hline Rata-rata skor total & $\mathbf{3 , 4 0}$ & Baik
\end{tabular}

Berdasarkan tabel 3 di atas, terlihat bahwa rata-rata skor total untuk setiap aspek sudah berada pada kriteria baik yang artinya modul telah praktis untuk digunakan dalam perkuliahan logika matematika. Selain itu, untuk mendapatkan informasi yang mendalam tentang penggunaan modul, peneliti juga menyediakan kolom komentar mahasiswa pada angket yang dibagikan.Hal ini dimaksudkan agar mahasiswa dapat leluasa menyampaikan pendapatnya.Pada umumnya mahasiswa memberikan komentar positif terhadap modul yang digunakan dalam perkuliahan, mereka merasa terbantu dengan adanya modul karena lebih mudah memahami materi logika matematika.Berikut salah satu contoh jawaban angket respon mahasiswa.

ANGKET RESPON MAHASISWA TERHADAP MODUL LOGIKA MATEMATIKA

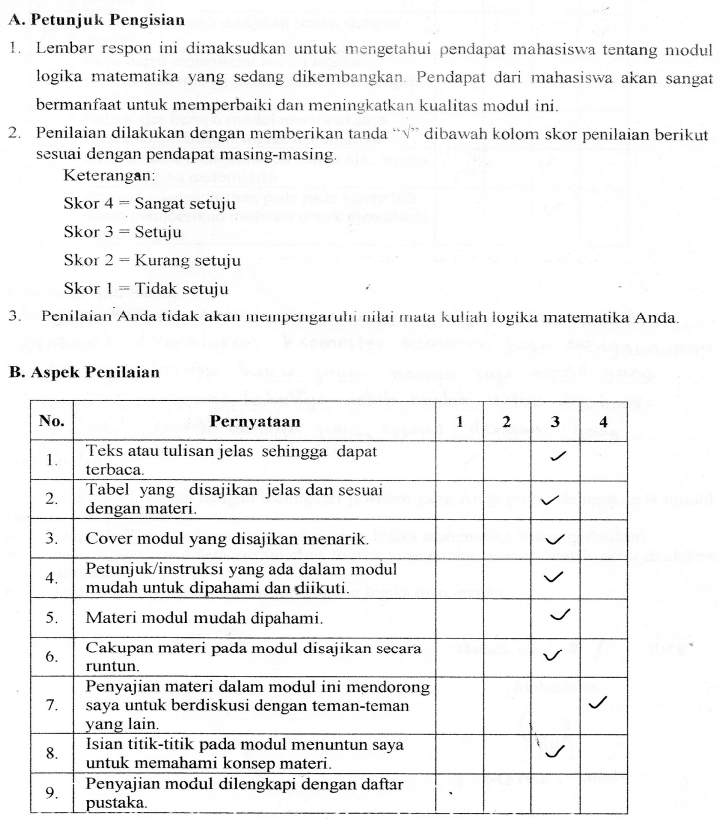

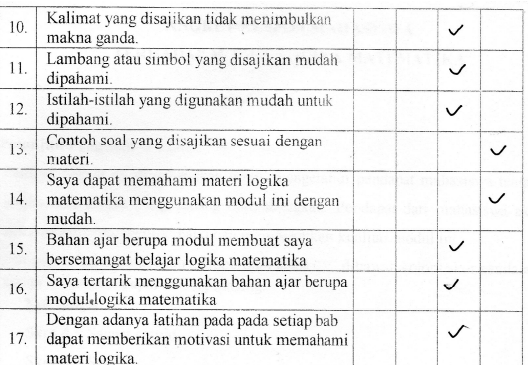

Komentar dan Saran

Mungkin kenapa materi menggunakan modul ini mudah dipahami dikarenakan semester kemaren juga menggunakan media ajar berupa buka juga. hanya saja modul yang digunakan sekarang baha'nya lebih mudah untuk dipahamidan contoh-contoh soalnya juga sesuai dengan yang ada pada materi dan lebih jelas.
Kesmpulan Sangat baik digunakan dalam perkuliahan logika matematika (tanpa perbaikan) Baik digunakan dalam perkuliahan logika matematika, namun masih perlu diadakan Tidak baik digunakan dalam perkuliahan logika matematika.

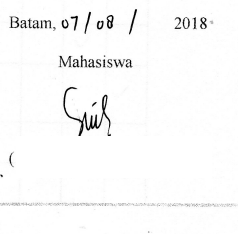

Gambar 5. Salah Satu Jawaban Angket Respon Mahasiswa 
Setelah diperoleh modul yang praktis langkah berikutnya yaitu mengetahui keefektifan modul yang dikembangkan. Efektif atau tidaknya modul diketahui dari nilai tes hasil belajar mahasiswa.Tes yang diberikan berupa tes uraian yang terdiri dari 3 soal.Deskripsi data hasil belajar disajikan pada tabel 4 berikut.

Tabel 4. Deskripsi Data Tes Hasil Belajar

\begin{tabular}{lc}
\hline Deskripsi Data & Nilai \\
\hline Rata-rata & 76,90 \\
Simpangan Baku & 16,41 \\
Varians & 269,42 \\
Skor Max & 100 \\
Skor Min & 42 \\
Skor Max Ideal & 100 \\
Skor Min Ideal & 0 \\
Jumlah Mahasiswa & 21 \\
\hline
\end{tabular}

Berdasarkan tabel 4 di atas, diperoleh rata-rata nilai tes hasil belajar mahasiswa setelah menggunakan modul yaitu 76,9 dan simpangan bakunya 16,41. Berikut contoh jawaban mahasiswa terhadap salah satu soal yang diberikan.

Setelah memahami materi pada modul logika matematika, kerjakanlah soal dibawah ini. Petunjuk: kerjakan soal yang dianggap mudah terlebih dahulu.

1. Susunlah tabel kebenaran dari pernyataan $(p \Leftrightarrow \sim q) \rightarrow[(\sim p \vee r) \wedge q]$ dan tentukanlah apakah pernyataan tersebut termasuk tautologi, kontradiksi atau kontingensi.

Gambar 6. Soal Logika Matematika

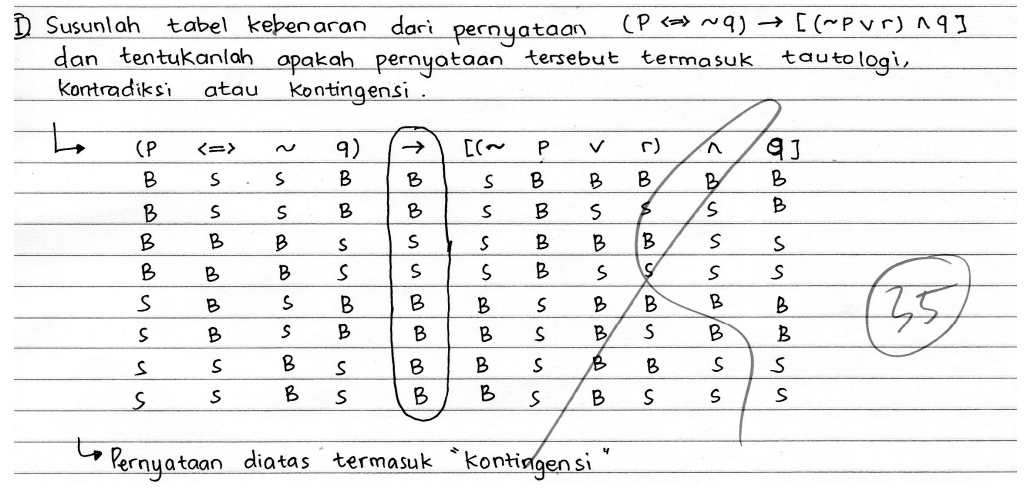

Gambar 7.Jawaban Mahasiswa 1

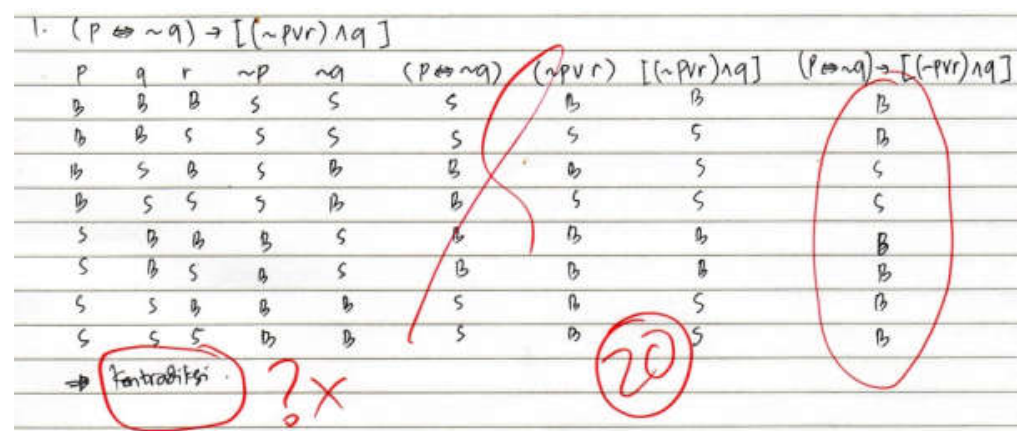

Gambar 8. Jawaban Mahasiswa 2 


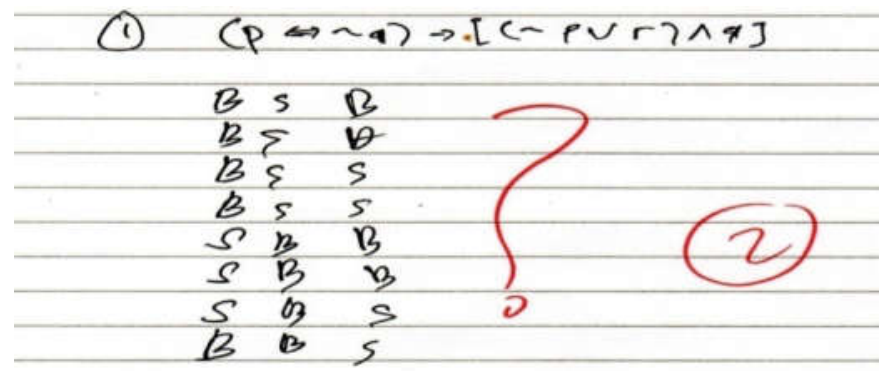

Gambar 9. Jawaban Mahasiswa 3

Berdasarkan Gambar 7, terlihat mahasiswa sudah memahami konsep tautologi, kontradiksi, dan kontingensi sehingga bisa membedakan ketiga sifat tersebut. Sedangkan pada Gambar 8, mahasiswa sudah benar dalam membuat tabel kebenaran tetapi keliru dalam membuat kesimpulan dari tabel kebenaran tersebut, jawaban yang benar yaitu kontingensi bukan kontradiksi.Selain itu, terdapat juga mahasiswa yang belum memahami konsep tabel kebenaran dan konsep tautologi, kontradiksi, kontingensi, hal ini terlihat dari jawaban yang diberikan pada Gambar 9, yang tidak memberikan kesimpulan apa-apa.

Selanjutnya akan dihitung persentase nilai mahasiswa berdasarkan skor yang diperoleh.

Tabel 5. Persentase Nilai Tes Hasil Belajar

\begin{tabular}{|c|c|c|c|}
\hline Rentang Skor & Nilai & Frekuensi & Persentase \\
\hline$x \geq 81$ & A & 10 & $47,62 \%$ \\
\hline $68 \leq x \leq 80$ & B & 5 & $23,80 \%$ \\
\hline $56 \leq x \leq 67$ & $\mathrm{C}$ & 3 & $14,28 \%$ \\
\hline $46 \leq x \leq 55$ & $\mathrm{D}$ & 2 & $9,53 \%$ \\
\hline$x \leq 45$ & $\mathrm{E}$ & 1 & $4,77 \%$ \\
\hline \multicolumn{2}{|c|}{ TOTAL } & 21 & $100 \%$ \\
\hline
\end{tabular}

Berdasarkan ketentuan bahwa modul dikatakan efektif apabila lebih dari $70 \%$ mahasiswa memperoleh nilai $\geq 68$. Dari tabel 5 di atas, terlihat persentase mahasiswa yang memperoleh nilai $\geq 68$ adalah sebesar $71,42 \%$. Maka dapat disimpulkan bahwa modul yang dikembangkan efektif dalam menunjang kompetensi mahasiswa pada mata kuliah logika matematika.

\section{KESIMPULAN}

Berdasarkan hasil pengembangan dan hasil ujicoba modul logika matematika berbasis PBL yang telah dilakukan dapat disimpulkan bahwa:

a. Modul logika matematika berbasis PBL yang dikembangkan praktis untuk digunakan dalam perkuliahan dengan pencapaian skor rata-rata total yaitu 3,40 termasuk kategori baik.

b. Modul logika matematika berbasis PBL yang dikembangkan efektif dalam menunjang kompetensi mahasiswa dengan perolehan nilai rata-rata hasil belajar yaitu 76,90 . Jumlah mahasiswa yang memperoleh nilai lebih dari 68 sebanyak 15 orang dari 21 orang mahasiswa atau sebesar 71,42\%. 


\section{DAFTAR PUSTAKA}

Andriadi, Fitraiani, D., \& Suhandri. (2018). Pengembangan Modul Matematika Berbasis Active Learning untuk Memfasilitasi Kemampuan Berpikir Kreatif Matematis. JURING: Journal for Research in Mathematics Learning, 1(1), 55-64.

Hidayati, K. (2013). Pengaruh Kemampuan Penalaran Logika Matematika Terhadap Prestasi Belajar Mahasiswa Pendidikan Madrasah Ibtidaiyah di STAIN Ponorogo. Kodifikasia, 7(1), 1-17.

Husniati, A., Suciati, \& Maridi. (2016). Pengembangan Modul Berbasis Problem Based Learning (PBL) Disertai Diagram Pohon pada Materi Fotosistesis Kelas VIII SMP Negeri 1 Sawoo. Jurnal Inkuiri, 5(2), 30-39.

Ikman, Hasnawati, \& Rezky, M. F. (2016). Effect of Problem Based Learning (PBL) Models of Critical Thinking Ability Students on The Early Mathematics Ability. International Journal of Education and Research, 4(7), 361-374.

Kusumah, Y. S. (1986). Logika Matematika Elementer. Bandung: Tarsito.

Mikrayanti. (2016). Meningkatkan Kemampuan Penalaran Matematis melalui Pembelajaran berbasis Masalah. Suska Journal of Mathematics Education, 2(2), 97-102.

NCTM. (2000). Principles and Standards of Mathematics Education. Retrieved from http://www.nctm.org

Ruseffendi, E. . (2005). Dasar-Dasar Penelitian Pendidikan Dan Bidang Non-Eksakta Lainnya. Bandung: Tarsito.

Sukirman. (2005). Logika dan Himpunan. Yogyakarta: Hanggar Kreator.

Tjiptiany, E. N., As'ari, A. R., \& Muksar, M. (2016). Pengembangan Modul Pembelajaran untuk Membantu Siswa SMA Kelas X dalam Memahami Materi Peluang. Jurnal Pendidikan: Teori, Penelitian, Dan Pengembangan, 1(10), 1938-1942.

Wahyudin. (2008). Pembelajaran dan Model-Model Pembelajaran (Pelengkap untuk Meningkatkan Kompetensi Pendagogis Para Guru dan calon Guru Profesional). Jakarta: CV. Ipa Abong.

Widoyoko, E. . (2017). Evaluasi Program Pembelajaran. Yogyakarta: Pustaka Pelajar. 